\title{
Vulvar Tuberculosis-A Rare Manifestation of the Disease
}

\section{Tuberculose vulvar - Uma manifestação rara da doença}

\author{
Cristina Bragança ${ }^{1}{ }^{10}$ Inês Gonçalves ${ }^{2}$ Luísa Guerreiro ${ }^{1}$ Maria Janeiro ${ }^{1}$ \\ ${ }^{1}$ Hospital José Joaquim Fernandes, Beja, Portugal \\ ${ }^{2}$ Hospital CUF Almada, Almada, Portugal \\ Address for correspondence Cristina Bragança, MD, Hospital José \\ Joaquim Fernandes, Rua Dr. António Fernando Covas Lima, 7801-849, \\ Beja, Portugal (e-mail: cristina.cbraganca@gmail.com).
}

Rev Bras Ginecol Obstet 2019;41:575-578.

\begin{abstract}
Tuberculosis is an infectious disease caused by Mycobacterium tuberculosis. According to data from the World Health Organization, this disease remains one of the leading causes of death worldwide. Although it most commonly affects the lungs, tuberculosis can compromise any organ. The present study reports a rare case of vulvar tuberculosis in a postmenopausal woman with a history of asymptomatic pulmonary and pleural

Keywords

- gynecology

- vulvar diseases

- tuberculosis

\section{Resumo}

Palavras-chave

- ginecologia

- doenças da vulva

- tuberculose tuberculosis, with no prior documented contact with the bacillus. Diagnosis was based on vulvar lesion biopsies, with histological findings suggestive of infection and isolation of $M$. tuberculosis by microbiological culture and polymerase chain reaction (PCR) essays. The lesions reverted to normal after tuberculostatic therapy.

A tuberculose é uma doença infeciosa causada pelo Mycobacterium tuberculosis. De acordo com dados da Organização Mundial de Saúde, esta doença mantém-se entre as principais causas de morte no mundo. Embora afete mais frequentemente os pulmões, a tuberculose pode comprometer qualquer órgão. O presente artigo relata um caso raro de tuberculose vulvar numa mulher na pós-menopausa, com antecedentes de tuberculose pleural e pulmonar assintomática, sem contato documentado com o bacilo. O diagnóstico foi feito com base na biópsia da lesão vulvar, com achados histológicos sugestivos da infeção e isolamento do M. tuberculosis por meios de cultura e pela técnica da reação em cadeia da polimerase (PCR). Após terapêutica tuberculostática, as lesões reverteram.
\end{abstract}

\section{Introduction}

Tuberculosis is an infectious disease caused by Mycobacterium tuberculosis. Although it most commonly affects the lungs, tuberculosis can compromise any organ. ${ }^{1}$ Genitouri-

(D) Cristina Bragança's ORCID is https://orcid.org/0000-0002-91113291.

received

January 9, 2019

accepted

June 13, 2019
DOI https://doi.org/

10.1055/s-0039-1695020.

ISSN 0100-7203. nary tuberculosis is the second most common form of extrapulmonary tuberculosis, even though female genital tuberculosis is rare. ${ }^{2-4}$ Incidence is higher in young women of reproductive age, and is often asymptomatic. ${ }^{5,6}$ The main manifestations, such as infertility, pelvic pain or abnormal uterine hemorrhage with fallopian tube or endometrial involvement, arise as a result of the infection reaching the upper genital tract, with atypical presentation in the vulva and vagina. ${ }^{6,7}$

Copyright $\odot 2019$ by Thieme Revinter Publicações Ltda, Rio de Janeiro, Brazil
License terms

(c) (1) 


\section{Case Report}

An 83-year-old Caucasian woman, nulliparous, with hypertension and no other known diseases, attended a gynecology appointment complaining of vulvar edema and a strongsmelling greenish vaginal discharge. Symptoms had been present for about 3 months. Her gynecological history was: menarche occurred at the age of 14 , with regular cycles and menses of 4 days. She became sexually active at the age of 22 and experienced menopause at the age of 50 . She never used any contraceptive and had had only one sexual partner. Upon examination, inflammation of the vulva and perineum was identified, with extensive poorly delimited erythematous lesions and scattered pustules. Hard edema of the left labia majora and small ulcers in the right perineal region were identified (- Fig. 1). Speculum and bimanual pelvic examination were normal, besides genital atrophy.

Samples of vulvar and vaginal exudates were collected for the detection of microorganisms. A biopsy of the lesion was taken, and a pelvic computed tomography (CT) was performed, due to suspected vulvar neoplasia. The woman was hospitalized for treatment of the vulvar infection, using quadruple therapy (flucloxacillin $500 \mathrm{mg}$ IV q8h, fluconazole $50 \mathrm{mg}$ per os q8h, metronidazole $500 \mathrm{mg}$ IV q8h, and amoxicillin and clavulanate $1.2 \mathrm{~g}$ IV q8h) without clinical improvement. Pelvic CT reported an atrophic uterus. No anomalies and no pelvic masses were identified. Vulvar and vaginal exudates were negative for microorganisms. Histological results using hematoxylin and eosin staining revealed an ulcerated stratified squamous epithelium, intense inflammatory granulomatous infiltrate, granuloma with giant multinucleate cells and necrosis. No malignancy or microorganisms were found (-Fig. 2).

Serologies were requested for sexually transmitted diseases and new samples were collected to detect Mycobacterium Tuberculosis. Serologies for syphilis, herpes, and HIV were negative. The interferon-gamma release assays (IGRA) test, with high sensitivity and specificity to active or latent tuberculosis infection, was positive. Histological tests with ZiehlNeelsen staining did not detect acid-fast bacilli, nor did Grocott methenamine silver staining detect fungus. Cultural examina-

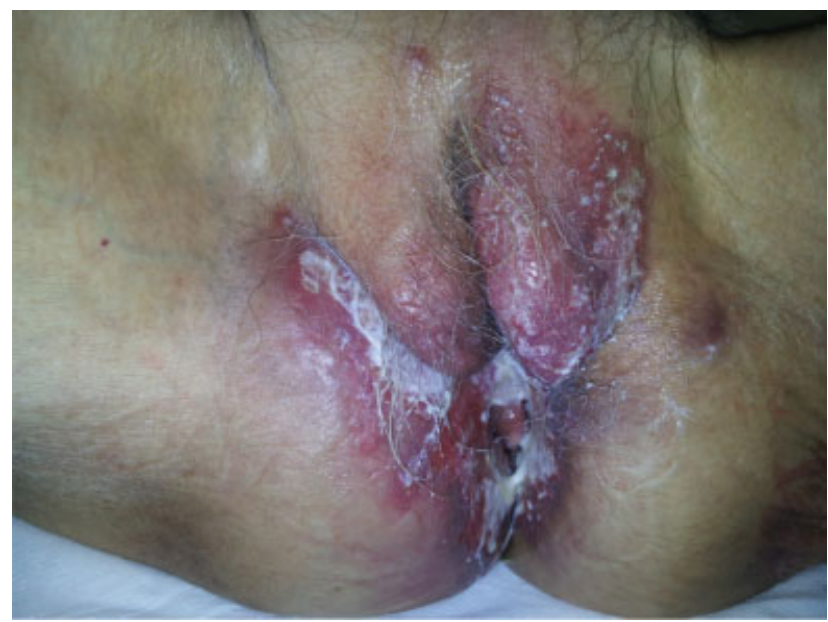

Fig. 1 Vulvar lesions at first appointment (white cream applied for symptom relief visible in image).

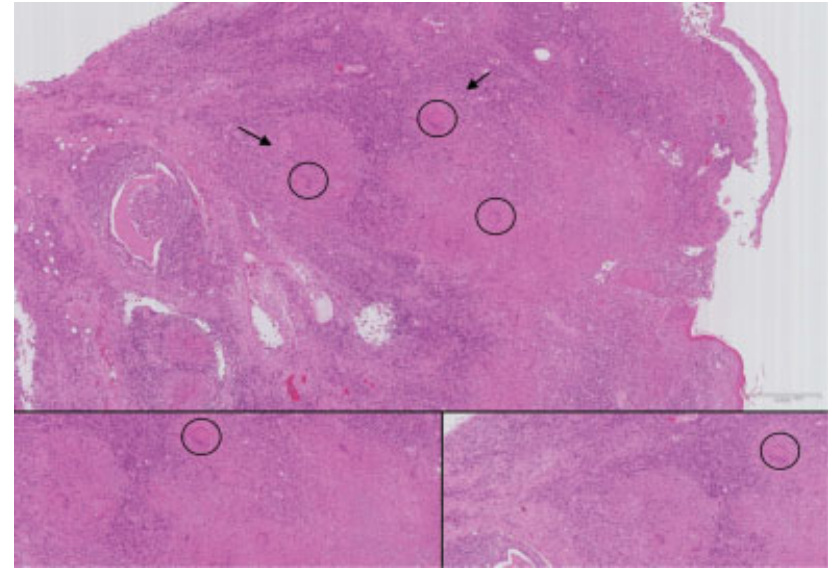

Fig. 2 Fragment of vulvar tissue showing stratified squamous epithelium with inflammatory infiltrate and granulomatous inflammation (arrows) with multinucleated Langerhans-type giant cells (circles) in superficial connective tissue (hematoxylin and eosin stain).

tion of the samples was positive for M. tuberculosis using the BacT/Alert 3D system (BioMériux, Lisboa, Portugal) and polymerase chain reaction (PCR) essays. Radiological findings in the thorax showed thickening and calcification of the left pleura, probably sequela of pachypleuritis calcarea, with diminished left lung capacity. The images revealed poorly defined, cotton-like radiodense lesions and diffuse linear lesions in the lung segments, suggesting bronchiectasis with subsequent fibrotic alterations. These findings were compatible with pleural and pulmonary tuberculosis sequelae, and it was not possible to safely exclude active infection ( - Fig. 3 ).

Standard tuberculostatic therapy was started and, one month after the treatment, improvement of the symptomatology initially presented was observed ( - Fig. 4 ).

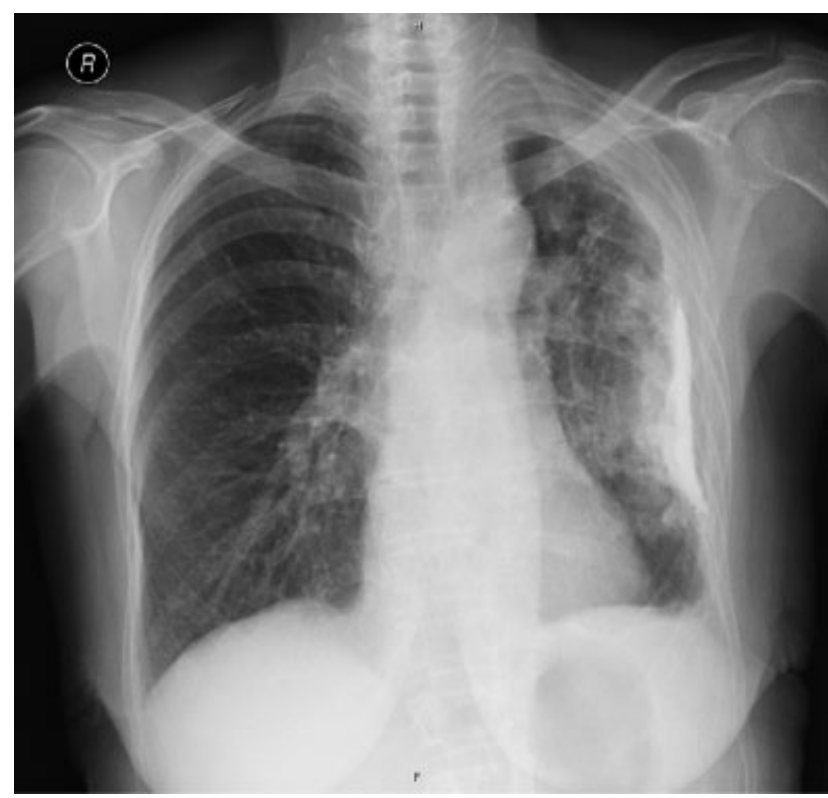

Fig. 3 Radiological findings in the thorax. 


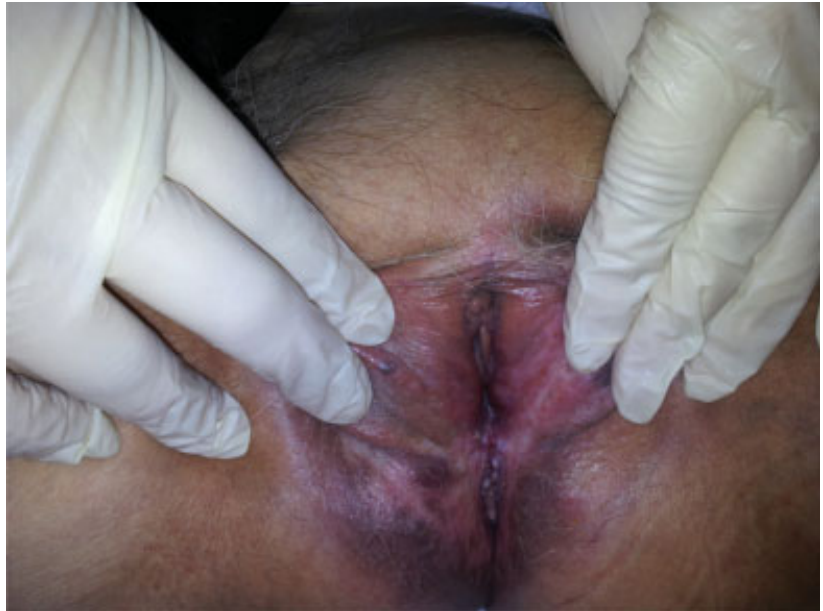

Fig. 4 Vulva after treatment.

\section{Discussion}

Tuberculosis is an infectious disease with high morbimortality, especially in underdeveloped countries. ${ }^{7}$ The World Health Organization estimates that more 10 million people developed tuberculosis in 2017: $90 \%$ were adults, and $58 \%$ of the 10 million people were men. More than $90 \%$ of cases occur in developing countries of all genitourinary tuberculosis cases. ${ }^{2}$ Vaginal and vulvar tuberculosis is rare, occurring in less than $1 \%$ of total cases. ${ }^{7}$ In Portugal, the incidence of tuberculosis is $2 / 1,000$ and mortality is $0.21 / 1,000{ }^{8}$ No vulvar tuberculosis cases have been reported there.

Female reproductive system tuberculosis may rarely occur as a primary infection, by direct inoculation during sexual intercourse with an infected partner, ${ }^{6}$ or as a secondary infection, arriving from affected organs via the blood or lymphatic system. ${ }^{2}$ This disease usually results from hematogenous dissemination from the lungs, ${ }^{9}$ by the reactivation of latent disease. There is usually a latency period of 5 to 40 years between the initial symptomatic or asymptomatic infection and tuberculosis in the genital and urinary tracts. ${ }^{2}$ Vulvar tuberculosis lesions are generally small superficial ulcers, with hypertrophy being a rare form of presentation. ${ }^{6,7}$ Often, hypertrophic lesions suggest malignancy, and the ulcers do not heal. ${ }^{10}$

Diagnosis is not easy, requiring a high level of suspicion. ${ }^{4-6}$ Only $2 \%$ of patients have a known tuberculosis history, about $75 \%$ have normal chest radiography and pelvic examination is normal in up to $43 \%$ of women. Genital tuberculosis characteristic histologic lesions are epithelioid cells granuloma with or without Langerhans giant cells. Central caseous necrosis, characteristic of tuberculous granuloma, is an uncommon late finding. ${ }^{5}$ In addition, caseomas and acid-fast bacilli are often absent in vulvar tuberculosis cases. ${ }^{11}$ Although isolation of the bacillus is the gold standard examination for diagnosis, ${ }^{10}$ it is known to be rarely found in the female genital tract. ${ }^{7}$ Currently, the DNA polymerase chain reaction to bacilli detection is widely used, presenting high sensitivity and specificity. ${ }^{5}$ Histologic examination is one of the most widely used to establish diagnosis, ${ }^{7}$ and the presence of typical granuloma is sufficient to confirm the diagnosis. ${ }^{6}$
Tuberculosis prevalence is higher in HIV-positive individuals and those with co-infection present a higher prevalence of extrapulmonary lesions; therefore, coinfection must always be excluded. ${ }^{5}$

The recommended treatment for genital tuberculosis is primarily pharmacological, with anti-bacilli therapy for 9 to 12 months, with surgical treatment being reserved to cases of persistent disease or symptomatic exacerbation. ${ }^{2}$ The vulvar lesion behavior provides a means to verify response to treatment; however, ideally, a new histologic exam must be performed. ${ }^{9}$

In our report, vulvar tuberculosis was probably a reactivation of latent infection, given the pulmonary and pleural sequelae. Due to the absence of pulmonary symptoms, Mycobacterium Tuberculosis was not studied in the sputum, which could have supported or excluded the diagnosis. However, a possible tuberculosis of the upper genital tract with extension to the vulvar region cannot be ruled out, taking into account the history of infertility, although the result of the pelvic CT was normal.

Typical histologic lesions of the vulvar biopsy indicated the diagnosis, and this hypothesis was confirmed by cultural and PCR isolation of M. tuberculosis. The resolution of the symptoms after the antibacterial therapy is a therapeutic trial that reinforces the diagnosis.

\section{Conclusion}

Tuberculosis remains a major problem in underdeveloped countries. Genital involvement is rare and often treated as a sexually transmitted disease. Although rare, this should always be considered when dealing with chronic vulvar lesions that do not respond to usual medical therapy.

\section{Conflicts of Interest}

The authors have no conflicts of interest to declare.

\section{Acknowledgements}

The authors would like to thank Dr. Carlos Quintana for the histological images, Rute Grou for the histological information, Dr. Rita Ramalho and Dr. Tiago Pereira for dermatological descriptions, Dr. Cláudia Ferreira for microbiological exams, Dr. Isabel Lima for radiological interpretation, and Dr. Conceição Margalha for the critical review of the manuscript.

\section{References}

1 Lyon S, Rossman M. Pulmonary tuberculosis. Microbiol Spectr 2017;5(01):. Doi: 10.1128/microbiolspec.TNMI7-0032-2016

2 Zajaczkowski T. Genitourinary tuberculosis: historical and basic science review: past and present. Cent European J Urol 2012;65 (04):182-187. Doi: 10.5173/ceju.2012.04.art1

3 Maiti K, Mishra S, Bera M, Pal D, Maiti M, Mondal PP. Primary vulvar tuberculosis presenting as multiple vulvar ulcers: a rare case report. UroToday Int J. 2013;6(03):39. Doi: 10.3834/uij.1944-5784.2013.06.13

4 Mallya V, Yadav YK, Gupta K. Vulval tuberculosis masquerading as vulval carcinoma. J Postgrad Med 2012;58(04):307-308. Doi: 10.4103/0022-3859.105463 
5 Ferreira C, Pinto E, Rocha I, Osório M, Felgueira E. Tuberculose genital como causa de infertilidade. Acta Obstet Ginecol Port 2013;7(03):219-222

6 Arakeri SU, Sinkar P. An unusual gross appearance of vulval tuberculosis masquerading as tumor. Case Rep Obstet Gynecol 2014;2014:815401. Doi: 10.1155/2014/815401

7 Tiwari P, Pal DK, Moulik D, Choudhury MK. Hypertrophic tuberculosis of vulva-a rare presentation of tuberculosis. Indian J Tuberc 2010;57(02):95-97

8 World Health Organization. Global Tuberculosis Report. Geneva: WHO; 2018http://www.who.int/iris/handle/10665/274453. Accessed December 10, 2018
9 Manoj K, Soma M, Ajay L, Ashish A, Rakesh S, Paliwal RV. Tubercular sinus of labia majora: rare case report. Infect Dis Obstet Gynecol 2008;2008:817515. Doi: 10.1155/2008/817515

10 Nanjappa V, Suchismitha R, Devaraj HS, Shah MB, Anan A, Rahim SN. Vulval tuberculosis - an unusual presentation of disseminated tuberculosis. J Assoc Physicians India 2012; 60:49-52

11 Mondal SK. Histopathologic analysis of female genital tuberculosis: a fifteen-year retrospective study of 110 cases in eastern India. Turk Patoloji Derg 2013;29(01):41-45. Doi: 10.5146/ tjpath.2013.01146 